\title{
The effects of PCB126 on intra-hepatic mechanisms associated with non alcoholic fatty liver disease
}

\author{
Marie-Pier Boucher ${ }^{3}$, Caroline Lefebvre ${ }^{3}$ and Natalie Ann Chapados ${ }^{1,2^{*}}$
}

\begin{abstract}
Background: Non alcoholic fatty liver disease (NAFLD) results from alteration in lipid synthesis and elimination mechanisms such as very-low density lipoprotein (VLDL) production and de novo lipogenesis. Persistent organic pollutants (POPs) are chemicals that were mostly used historically as pesticides, solvents, flame retardant, and other applications. Among POPs, polychlorinated biphenyls (PCB) have been recognized to be of environmental and potential toxicologic concerns. Specifically, PCB126 could act as endocrine disruptors and has recently been associated with hepatic fat accumulation. The purpose of the study was to investigate the effects of PCB126 on the molecular development of NAFLD using hepatocyte and rat models.

Methods: Hepatocytes were exposed to PCB 126 for $72 \mathrm{~h}$ and lipid accumulation in cells was quantified by Oil-Red-O. Rats were injected with a single dose of PCB126 or vehicle. Seven days later, liver triglycerides (TAG) content was measured along with protein quantification of hepatic microsomal triglyceride transfer protein (MTP), sterol regulatory element-binding protein 1c (SREBP1c) and diacylglycerol O-acyltransferase 2 (DGAT-2).

Results: Exposure to PCB126 resulted in significant increases of lipid accumulation in hepatocytes $(38 \%, P<0.05)$ and hepatic TAG concentrations $(64 \%, P<0.001)$ in rats compared to respective control groups. Rats with fatty livers depicted lower MTP $(40 \%, P<0.02)$, higher SREBP1c $(27 \%, P<0.05)$ and DGAT-2 $(120 \%, P<0.02)$ protein content levels compared to Placebo group in rats.
\end{abstract}

Conclusions: It seems that exposure to PCB126 has an important emerging role in the pathophysiology of NAFLD by 1) altering elimination mechanisms such as VLDL synthesis and secretion, through MTP; and 2) increasing hepatic TAG synthesis mechanisms through DGAT 2 and SREBP1c.

Keywords: Steatosis, Environmental contaminants, Liver, Rats

\section{Background}

Liver plays an essential role in the biogenesis of major metabolites such as lipids. However, an important increased in hepatic fat depot leads to the development of NAFLD. NAFLD is the most prevalent liver disease in North America and reaching approximately $20 \%$ of the population worldwide, and affecting both adults and children $[1,2]$. NAFLD has become a common cause

\footnotetext{
* Correspondence: n.chapados@gmail.com

'Institut de recherche de l'Hôpital Montfort, Hôpital Montfort, 713 Montreal Road, Ottawa, ON K1K 0T2, Canada

${ }^{2}$ School of Human Kinetics, Faculty of Health Sciences, University of Ottawa, Ottawa, ON, Canada

Full list of author information is available at the end of the article
}

of chronic metabolic diseases such as steatohepatitis, diabetes [3] and metabolic syndrome [4]. Historically NAFLD was linked to overnutrition, physical inactivity and pharmacology. However, emerging studies have demonstrated that additional contributing factors may play a role in the development of NAFLD, such as persistent organic pollutants (POPs).

Persistent organic pollutants are chemicals that were mostly used historically as pesticides, solvents, and flame-retardants and have been released in the environment. In North America, POPs have been recognized to be of environmental and potential toxicologic concern, as a result, a variety of POPs have been banned from use 
since the late 1970's [5]. However, due to their persistence and lipophilicity, these compounds will remain present in the environment for decades and accumulate in living organisms [6]. POPs also accumulate in adipose tissue and are continuously released from adipose tissue to the circulation and to vital organs with lipid content [7]. In humans, a National Health and Nutrition Examination Survey (NHANES) study showed that the total participants had detectable circulating POPs levels [8]. POPs regroup polychlorinated biphenyls (PCBs), a family of 209 different congeners. A total of 1.3 million tons of PCBs were manufactured prior 1977 for use in electrical and other industrial applications [9]. PCB126 is the most potent and ubiquitous in the environment amongst congeners [10]. Recent studies have reported that the presence of PCB126 could act as endocrine disruptors at the liver level and lead to fatty liver [11].

Hepatic lipid accumulation results from altered intrahepatic TAG elimination and synthesis mechanisms. Specific key-molecules such as MTP is involved in lipid elimination pathways through VLDL production and secretion, while synthesis pathways regroup DGAT-2 and SREBP1c.

Hepatic VLDL production is a complex process involving several enzymes to carry TAG from liver to peripheral tissues [12]. MTP plays a pivotal role in the assembly and secretion of apoB-containing lipoproteins [13]. MTP is a heterodimeric protein expressed on the luminal side of ER composed of a catalytic subunit of $97 \mathrm{kDa}$ and a multifunctional protein of $55 \mathrm{kDa}$, disulfide isomerase [14]. Molecular processes such as fatty acid synthesis and esterification also regulate hepatocytes TAG content. In the liver, DGAT has a role in synthesizing TAG from either fatty acids synthesized de novo or from fatty acids taken up from the circulation. Two DGAT enzymes were identified, DGAT1 and DGAT2. While DGAT1 seems to be associated to TAG synthesis and VLDL secretion stimulation [15], DGAT2 appears to catalyze the final step in the pathway leading to de novo synthesis and intracellular accumulation of TAG [16]. SREBPs are major transcription factors that regulate the expression of genes involved in lipid synthesis in the liver. Three isoforms exist, SREBP-1a, -1c and $-2[17,18]$. SREBP-2 activates genes involved in cholesterol metabolism, whereas SREBP-1 regulates genes involved in the metabolism of fatty acids [240]. SREBP-1c is the predominant isoform expressed in liver [18] and is mostly responsible for the expression of genes involved in hepatic fatty acid biosynthesis [19].

Over the last decade, interactions of PCB126 with nervous [20] and reproductive [21] metabolic activities for instance, have attracted much interest. However, the effects of PCB126 on the liver, specifically on the underlying molecular mechanisms leading to NAFLD have not yet been defined. Therefore the purpose of this research study is to understand the molecular effects of PCB126 exposure on VLDL production, estimated through MTP, and on hepatic lipid synthesis, via DGAT2 and SREBP1c using human cell culture and animal model.

\section{Methods \\ Cell culture}

PCB126 was obtained from Ultra Scientific (North Kingstown, RI, USA) and dimethyl sulfoxide (DMSO) was obtained from Sigma-Aldrich (St. Louis, MO, USA). PCB126 was dissolved in DMSO as stock solution and diluted with Differentiation Medium (Zenbio Inc, North Carolina, USA, cat\# DM-2) to specific concentration before being added to the cells in culture. The final concentration of DMSO was never greater than $0.3 \%(\mathrm{v} / \mathrm{v})$. Human hepatocytes (ZenBio Inc., Durham, NC) were initially plated at a density of $9.410^{4}$ cells/well. Following a 6 to $8 \mathrm{~h}$ incubation period for cell attachment, hepatocytes were exposed to PCB126 [2.5uM] for $72 \mathrm{~h}$ [22]. Control group was treated in DMSO (0.3 \%) and chloroquine $[25 \mathrm{uM}]$ served as a positive control. Cells were incubated at $37{ }^{\circ} \mathrm{C}$ in a humidified $95 \%$ air-5 \% $\mathrm{CO}_{2}$ atmosphere incubator in 48 well plates.

Lipid quantification was assessed in human hepatocytes using steatosis colorimetric assay (Cayman Chemical Company, Ann Arbor, Michigan).

\section{Animal care}

Female Sprague-Dawley strain rats (Charles River, StConstant, Quebec, Canada), weighing 200-250 g upon their arrival were housed in pair and had ad libitum access to food and tap water. Their environment was controlled in terms of light (12:12-h light-dark cycle starting at 6:00 AM), humidity and room temperature $\left(20-23{ }^{\circ} \mathrm{C}\right)$. All rats were fed a standard diet (Harlan 2018 Rodent Diet, Harlan Teklad Laboratory) and had access to water ad libitum. The sham group received a single ip injection of corn oil $(0.14 \mathrm{ml} / \mathrm{kg})$ while experiment group received PCB126 $(1.05 \mathrm{umol} / \mathrm{kg})$ dissolved in corn oil [23]. All procedures were approved by the Animal Care Committee of the University of Ottawa and adhered to the guidelines established by the Canadian Council on Animal Care.

\section{Tissue sampling}

Following 7 days after the injection, and after complete anaesthesia (sodium pentobarbital, $65 \mathrm{mg} / \mathrm{kg}$, ip.), the abdominal cavity was rapidly opened following the median line of the abdomen. Blood was rapidly $(<45 \mathrm{~s})$ drawn from the abdominal vena cava $(\sim 4 \mathrm{ml})$ and transferred in tubes pretreated with EDTA (15\%). Blood was centrifuged (3000 g for $10 \mathrm{~min}, 4{ }^{\circ} \mathrm{C}$ ) and the plasma were stored at $-80{ }^{\circ} \mathrm{C}$ until analyses. The liver was 
excised, the median lobe immediately frozen used for triacylglycerol determination and protein quantification.

\section{Western immunoblotting}

Briefly, $200 \mathrm{mg}$ of liver was homogenized in Lysis Buffer (extraction buffer) with $\mathrm{Na} 3 \mathrm{VO} 41 \mathrm{mM}$ and protease inhibitor cocktail using a polytron, sonicated and centrifuged at $13,000 \mathrm{~g}, 4{ }^{\circ} \mathrm{C}$ for $20 \mathrm{~min}$. The infranatant was collected with a blunt-tipped Pasteur pipette and stored at $-80{ }^{\circ} \mathrm{C}$ until protein determination. All samples (50 $\mu \mathrm{g}$ of proteins) were separated on a $10 \%$ SDSpolyacrylamide gel and electrotransferred onto nitrocellulose membranes. Membranes were blocked 1-h in Phosphate-buffered saline containing $0.05 \%$ Tween 20 (PBST $0.05 \%$ ) and $5 \%$ non-fat dry milk at $4{ }^{\circ} \mathrm{C}$. The blot was then incubated with primary antibody overnight. After five washes in PBST (0.05\%), the membrane was incubated for $45 \mathrm{~min}$ with secondary antibody (Novus Biologicals, Littleton, $\mathrm{CO}$ ) at room temperature. Then the membrane was washed five times for 15 min each time in PBST $(0.05 \%)$ before revealing with West Pico (Fisher Scientific Company). The resulting signal was acquired with ChemiDoc-It Imaging System (Fisher Scientific Company) and the bands were quantified with the use VisionWorks ${ }^{\circ} \mathrm{LS}$ (UVP, LLC, Upland, CA) software and expressed as arbitrary units. Equal protein loading was determined using $ß$-actin (Sigma, Saint Louis, Missouri, USA).

\section{Analytical procedures}

Plasma TAG levels were determined with an enzymatic colorimetric assay available from SIGMA (Saint Louis, Missouri, USA). Liver TAG concentrations were estimated from glycerol released after ethanolic $\mathrm{KOH}$ hydrolysis by using commercial kits from SIGMA (Saint Louis, Missouri, USA).

\section{Statistical analysis}

Values are expressed as mean \pm S.E. Statistical analyses were performed using a one-way analysis of variance (ANOVA) for non-repeated measures. Fisher's LSD post hoc test was used in the event of a significant $(p<0.05)$ F ratio. Significance was accepted at $p<0.05$. All analyses were performed using SPSS Statistics 20.0, SPSS Inc., Illinois, USA.

\section{Results}

Cells

As illustrated in Fig. 1a hepatocytes lipid accumulation seen by microscope by Oil-Red-O and (B) measured by colorimetry (OD $490 \mathrm{~nm}$ ) after Oil-Red-O extraction from lipid droplets, was $38 \%$ greater in cells treated with PCB126 $[2.5 \mathrm{uM}]$ for $72 \mathrm{~h}\left(0.23 \pm 0.01 \mathrm{OD}_{490 \mathrm{~nm}}\right)$ compared to Control (DMSO) $\left(0.17 \pm 0.007 \mathrm{OD}_{490 \mathrm{~nm}}\right)$ group $(P<0.001)$. Although PCB126 treated cells depicted $14 \%$ higher lipid content than Chloroquine, a potential lipid droplet infiltration inducer $(0.20 \pm 0.01$ $\left.\mathrm{OD}_{490 \mathrm{~nm}}\right)$, statistical significance was not reached $(P<0.08)$. The cells treated with Chloroquine depicted $21 \%$ higher lipid content than the Control group $(P<0.04)$.

\section{Rats}

PCB126 injections in rats resulted in higher hepatic TAG content (64\%) compared to Control group injected with Corn oil $(21.3 \pm 1.3$ vs $35.2 \pm 3.1 \mathrm{mg} / \mathrm{g} ; P<0.001)$ (Fig. 2). Rats treated with PCB126 had $80 \%$ more plasma TAG compared to Corn Oil group $(0.35 \pm 0.06$ vs $0.64 \pm 0.08 \mathrm{mM}, P<0.02$ ) (Fig. 3). All hepatic protein contents are expressed in arbitrary units (AU). Immunoblotting of MTP resulted in a $40 \%$ decrease in PCB126injected rats compared to Corn Oil group $(1.4 \pm 0.1$ vs $0.8 \pm 0.1 \mathrm{AU} ; P<0.02$ ) (Fig. 4). In contrast, protein content of DGAT-2 revealed to be $120 \%$ higher $(1.29 \pm 0.2$

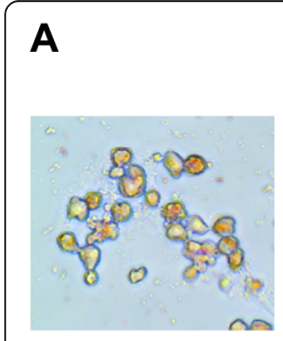

Control

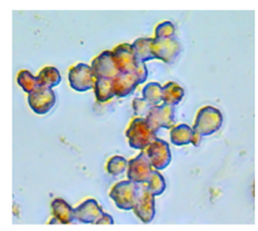

Chloroquine

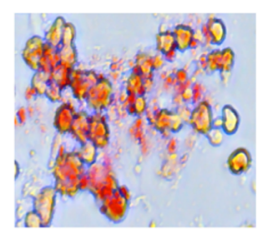

PCB126

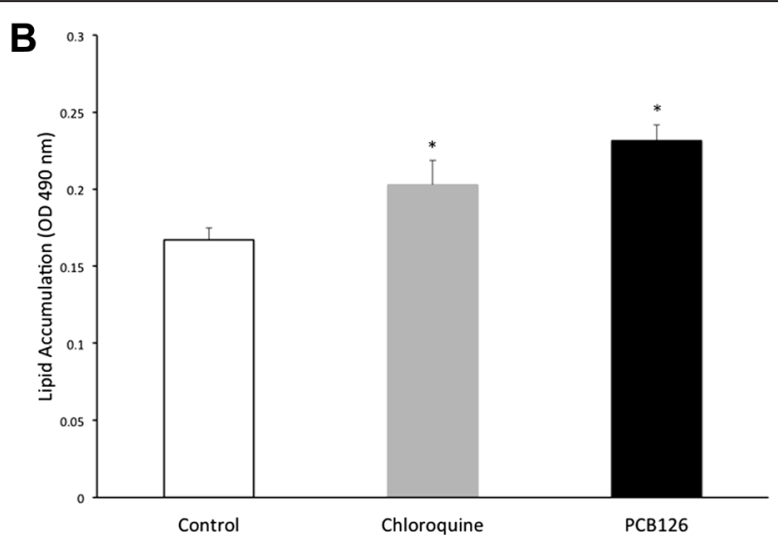

Fig. 1 Lipid accumulation in hepatocytes. (a) Neutral lipid staining in hepatocytes using Oil-Red-O exposed to DMSO (Control), Chloroquine and PCB126 [2.5 $\mu \mathrm{M}$ ] viewed by light microscopy (magnification 40x). (b) Lipid quantification by colorimetry after dye extraction from lipid droplet (OD $490 \mathrm{~nm}$ ). *Significantly different from Control rats $p<0.05 . n=8-11$. Control = White; Chloroquine $=$ Grey; PCB126 $=$ Black 


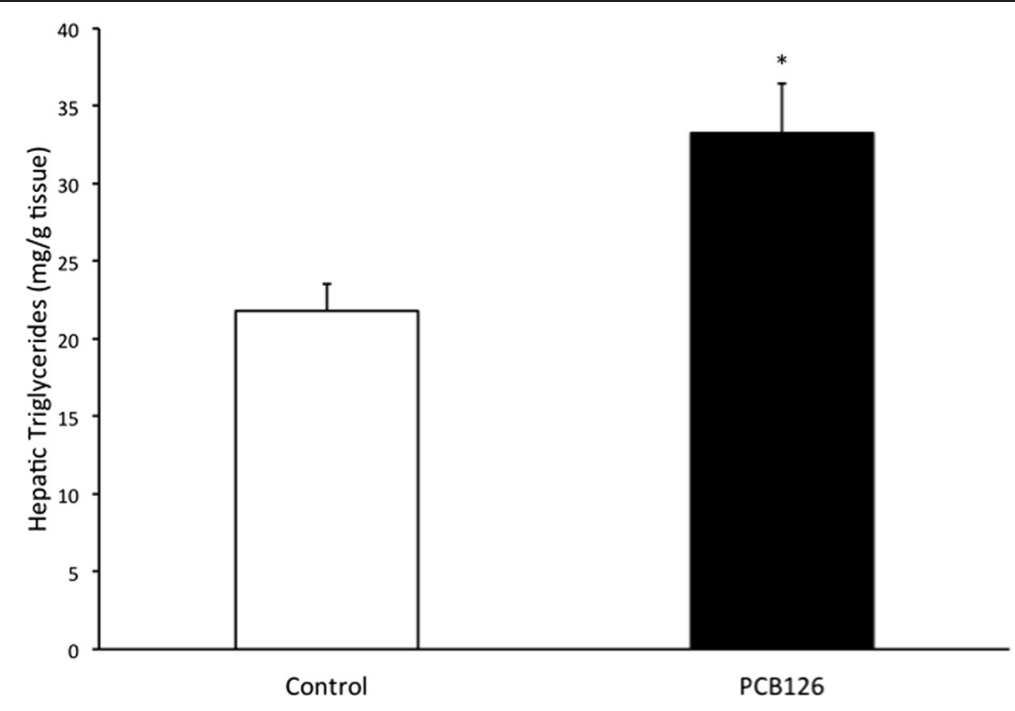

Fig. 2 Hepatic TAG content (mg/g). *Significantly different from Control $p<0.001 . n=9-11$. Control = White; PCB126=Black

vs $2.85 \pm 0.6 \mathrm{AU} ; P<0.02$ ) (Fig. 5) and SREBP1c was $26.5 \%$ greater $(0.87 \pm 0.07$ vs $1.09 \pm 0.07 \mathrm{AU} ; P<0.05)$ (Fig. 6) compared to control rats.

\section{Discussion}

In the present study, we observed that seven days of exposure to PCB126 lead to significant increases of lipid content in hepatocytes and in liver of rats. Our results strongly suggest that the presence of PCB126 is related to important hepatic fat accumulation. Accordingly, Wahlang et al. (2013) revealed that PCB 153 exposure in high fat-fed mice was associated with an increased hepatic TAG content in $\mathrm{C} 57 \mathrm{Bl} / 6 \mathrm{~J}$ mice compared to vehicle control group [24]. While, PCB-77 induced obesity in
C57B/6 mice and promoted differentiation of 3T3L1 adipocytes [25]. Together, these results imply an important association between PCBs exposure and increased fat accretion.

There are likely multiple factors involved in hepatic fat accumulation. We report an important decrease in MTP protein content in PCB126 treated rats compared to Corn oil injected group (Fig. 4). Deficiency of MTP gene in mice $[26,27]$ and gene polymorphism in humans [28] have been associated with the development of NAFLD. Also, pharmacological inhibition of MTP in rats and humans increased liver TAG content ranging from 30$1000 \%$ compared to control counterparts [29, 30]. Together, these results suggest that variations of the

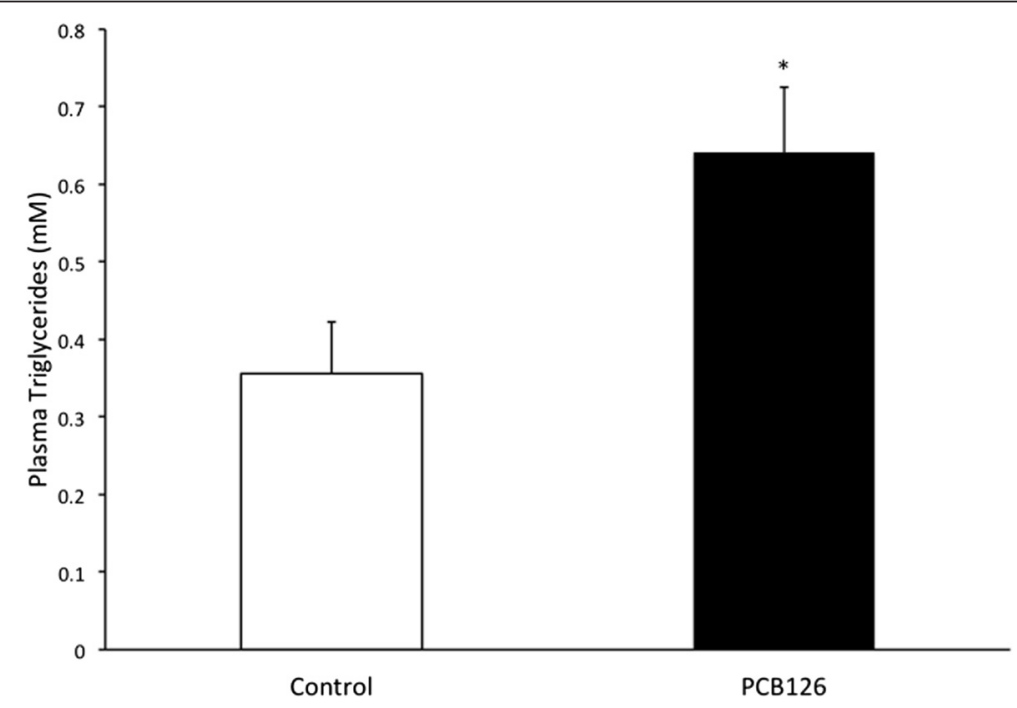

Fig. 3 Plasma Triglycerides concentrations $(n M) . n=7$. *Significantly different from Control group $p<0.02$. Control $=$ White; PCB126 $=$ Black 


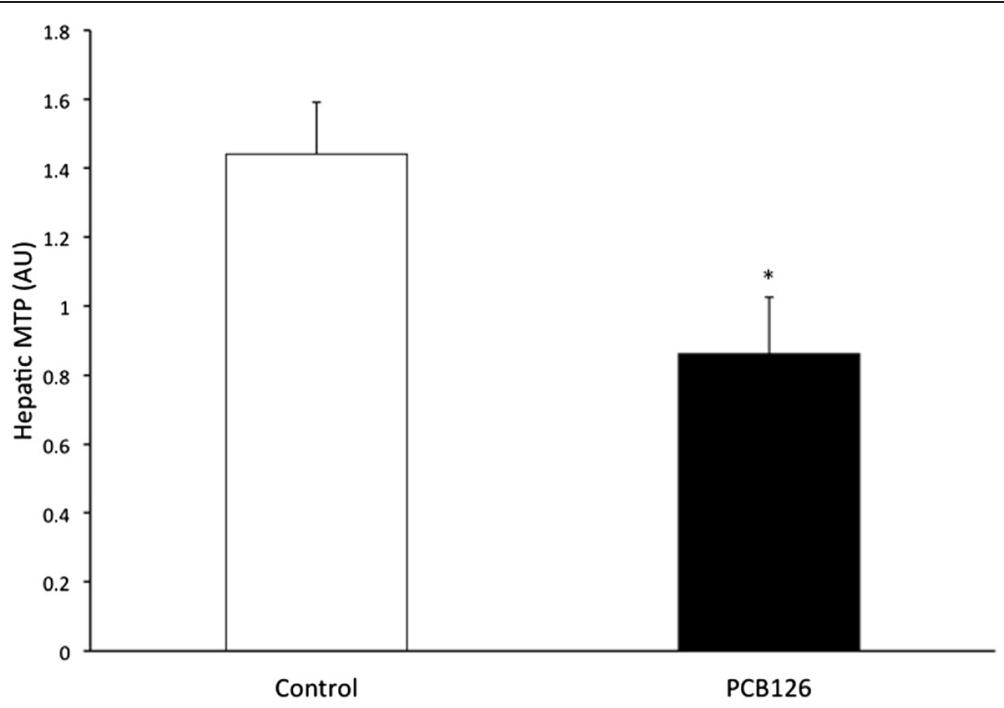

Fig. 4 MTP. Western blotting of MTP measured by optical density (OD). $n=8$. *Significantly different from Control rats $p<0.02$. Control $=$ White; PCB126 $=$ Black

expression and activity of MTP significantly affect hepatic lipid. However, to our knowledge there are no published studies on the effects of PCBs on hepatic MTP content and liver TAG accumulation. Therefore in our study, we can conclude that an altered expression of MTP resulting from PCB126 exposure might potentially cause important TAG accumulation in hepatocytes.

MTP plays a crucial role in the synthesis and hepatic VLDL secretion, thus on plasma TAG levels. Pharmacological inhibition of MTP has been mainly used in the treatment of hypertriglyceridemia in humans (Cuchel 2013; Raval 2012). Administration of a MTP inhibitor for two weeks resulted in a $600 \%$ increase in concentrations of TAG liver and a decrease of $100 \%$ of plasma TAG in comparison to control rats [31]. In mice, deletion or deficiency of hepatic MTP gene results in alteration of the VLDL secretion, reflected by significantly lower plasma concentrations of plasma triglycerides levels compared to control mice [26, 27, 32]. Conversely, an increased MTP protein content (161 \%) in the liver results in lipoprotein overproduction $(30 \%)$ in a fructose-fed hamster model of insulin resistance [33-35]. Although, our results reveal that despite the fact that MTP content was lower by $40 \%$, PCB126 injected rats in

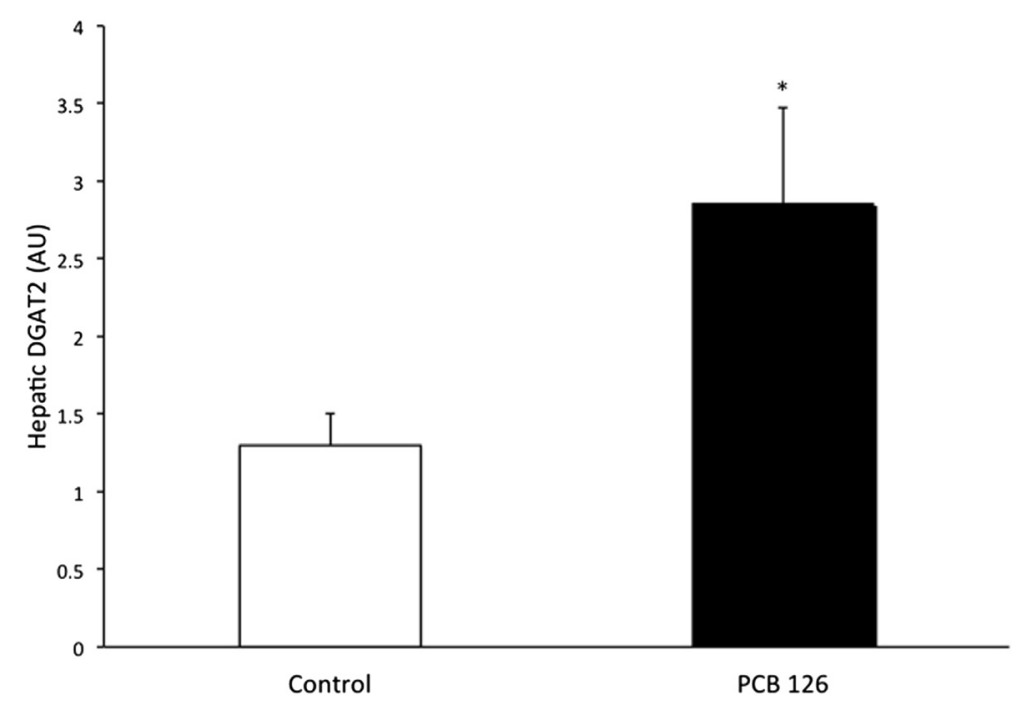

Fig. 5 DGAT2. DGAT2 was quantified by optical density (OD) using Western Blot. $n=5-7$. ${ }^{*}$ Significantly different from Control group $p<0.02$. Control $=$ White; $\mathrm{PCB} 126=$ Black 


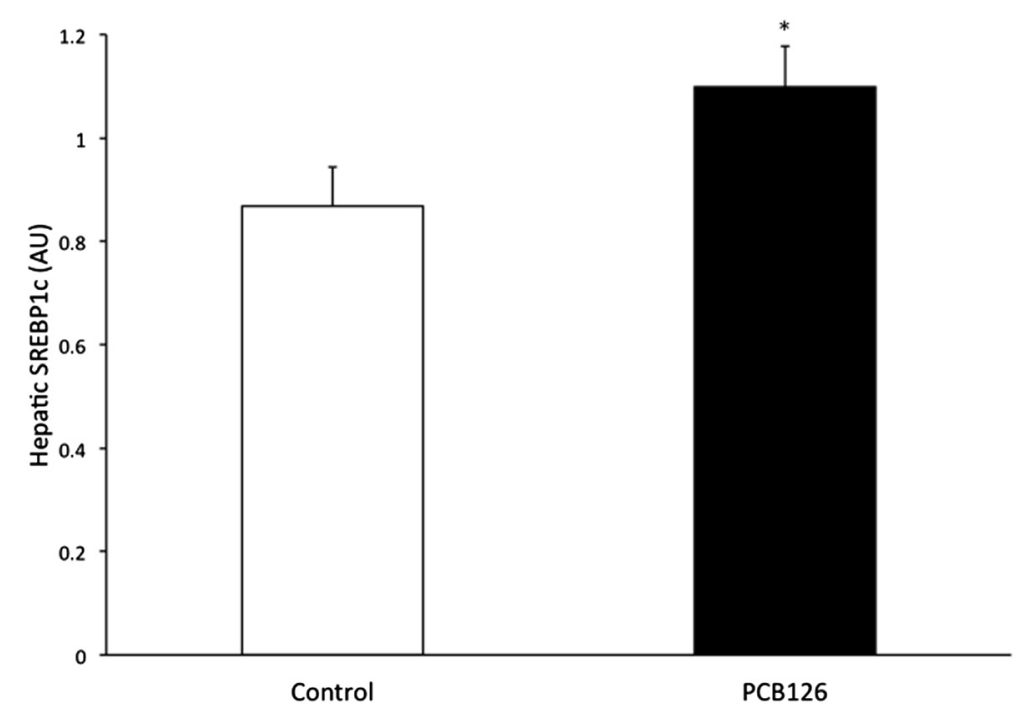

Fig. 6 SREBP1C. SREBP1C protein content measured by Western Blot and reported by optical density (OD). $n=8$. *Significantly different from Control rats $p<0.05$. Control $=$ White; PCB126 $=$ Black

our study showed nearly $80 \%$ higher plasma TAG concentrations than in control group (Fig. 3). These results are in line with several studies that have reported positive associations between PCBs and serum lipid in humans [36] and animals [37-39]. Mice had significant increase $(269 \%)$ in plasma TAG concentrations following oral administration of Aroclor 1254 for 14 days when compared with the control group [39]. As well, continuous orally daily exposure of various concentrations of Aroclor 1254 monkeys for 152 weeks in female rhesus was associated with increased in plasma TAG ranging from 30-56 \% [37]. Whereas MTP content was lower in our PCB126 exposed rats, we hypothesize that increases in plasma TAG levels may occur due to increased hepatic synthesis of TAG and production of larger VLDL particles. Production of VLDL with a larger size implies that fewer particles are being secreted to account for the similar TG production rates. In support of our hypothesis, one study reported a $30 \%$ increase in size of VLDL particles measured directly in the ER in male rats injected with PCBs [40]. Furthermore, in normal and T2D subjects, an overproduction of large VLDL particles is the major determinant of plasma TG levels and is mainly caused by liver fat content $[41,42]$.

Hepatic TAG content is partly regulated by fatty acid synthesis and esterification processes. DGAT2 catalyzes the final step in the G3P pathway leading to TAG synthesis. Our results revealed a substantial increase of $120 \%$ in hepatic DGAT2 protein content in our PCB126 treated rats compared to Corn oil group (Fig. 5). In line with our results, a recent study reported that DGAT-2 gene was differentially expressed (4.8-fold) in mouse lungs after 3-weeks of polluted ambient air exposure relative to control mouse [43]. Mice overexpressing hepatic DGAT2 showed a $260 \%$ increase in liver TAG concentrations [44]. While suppression of DGAT2 with antisense oligonucleotide treatment improves hepatic steatosis in a diet induced NAFLD [45] and obesity [46, 47] rat models. On the whole, these results suggest an important contributing role of DGAT2 in lipid accumulation and possibly leading to the development of NAFLD in our rats contaminated with PCB126.

Moreover, a recent study has reported that DGAT2 is specialized for glycerol 3-phosphate (G3P) incorporation into TAG, however it seems that the origin of these G3P are not from exogenous preformed fatty acid [48]. A possibility emerged that DGAT2 may be specialized for the utilization of de novo synthesized fatty acids [49]. Endogenously fatty acid synthesis occurs predominantly through de novo lipogenesis (DNL), both liver and adipose tissue. SREBP1c has been closely related to development of hepatic steatosis $[50,51]$ and hypertriglyceridemia [50]. Our results shows that our steatotic rats exposed to PCB126 depicted significantly higher SREBP1c protein concentration in their livers (Fig. 6). Similarly, a significant increase in the expression level of SREBP1c was induced in rats fed farm salmon containing various POPs [52].

\section{Conclusions}

Environmental pollutants have emerged as new contributing actors for their suspected endocrine and metabolic disruption activity leading to the development of NAFLD. The results emerging from this study bring valuable molecular information on how lipotoxic compounds such as PCB126 interfere with the normal 
functioning of vital metabolic pathways in the liver and are clearly associated with the molecular development of NAFLD.

A potential weakness of this study includes the i.p. route of administration of PCB126 and that a single dose of PCB 126 was used. PCBs are known to concentrate within adipose tissue and liver. Although PCB 126 levels were not measured in our livers, we expect them to be in line with to those in the National Toxicology Program Report [53]. Further in vivo studies are needed to more fully understand the mechanisms involved in PCB126 induced NAFLD. It already been reported that alteration in oxidative pathways may lead to ectopic fat accumulation in various organs including liver [54, 55]. Also, simultaneous co-exposures to chemicals and whether they may act in an additive, synergistic, or antagonistic manner must be taking in account in future study designs.

\section{Competing interests}

None of the authors have any competing interests in the manuscript.

\section{Authors' contribution}

MPB carried out the molecular studies on rats and helped drafted the manuscript. CL carried out the cell studies and revised the manuscript. NAC conceived of the study and its design, coordinated and helped to draft the manuscript. All authors read and approved the final manuscript.

\section{Acknowledgements}

This project was founded by the Natural Sciences and Engineering Research Council of Canada (NSERC 418312-2012) (to NAC).

\section{Author details}

${ }^{1}$ Institut de recherche de l'Hôpital Montfort, Hôpital Montfort, 713 Montreal Road, Ottawa, ON K1K 0T2, Canada. ${ }^{2}$ School of Human Kinetics, Faculty of Health Sciences, University of Ottawa, Ottawa, ON, Canada. ${ }^{3}$ La Cite, Ottawa, ON, Canada.

Received: 15 July 2015 Accepted: 26 November 2015

Published online: 10 December 2015

\section{References}

1. Vernon H, Puhl A, Reinhart C. Systematic review of clinical trials of cervical manipulation: control group procedures and pain outcomes. Chiropr Man Ther. 2011;19(1):3. doi:10.1186/2045-709X-19-3.

2. Williams CD, Stengel J, Asike MI, Torres DM, Shaw J, Contreras M, et al. Prevalence of nonalcoholic fatty liver disease and nonalcoholic steatohepatitis among a largely middle-aged population utilizing ultrasound and liver biopsy: a prospective study. Gastroenterol. 2011;140(1):124-31. doi:10.1053/j.gastro. 2010.09.038.

3. Farrell GC, Larter CZ. Nonalcoholic fatty liver disease: from steatosis to cirrhosis. Hepatol. 2006;43(S1):S99-S112.

4. den Boer M, Voshol PJ, Kuipers F, Havekes LM, Romijn JA. Hepatic steatosis: a mediator of the metabolic syndrome. Lessons from animal models. Arterioscler Thromb Vasc Biol. 2004;24(4):644-9. doi:10.1161/01.ATV. 0000116217.57583.6e.

5. United States Environmental Protection Agency. The Foundation for Global Action onPersistent Organic Pollutants: A United States Perspective. 2002. EPA/600/P-01/003F NCEA-I-1200. www.epa.gov.

6. Haddad S, Poulin P, Krishnan K. Relative lipid content as the sole mechanistic determinant of the adipose tissue:blood partition coefficients of highly lipophilic organic chemicals. Chemosphere. 2000:40(8):839-43.

7. Lee DH, Porta M, Jacobs Jr DR, Vandenberg LN. Chlorinated persistent organic pollutants, obesity, and type 2 diabetes. Endocr Rev. 2014;35(4):557-601. doi:10.1210/er.2013-1084.
8. Cave M, Appana S, Patel M, Falkner KC, McClain CJ, Brock G. Polychlorinated biphenyls, lead, and mercury are associated with liver disease in American adults: NHANES 2003-2004. Environ Health Perspect. 2010;118(12):1735-42. doi:10.1289/ehp.1002720.

9. Breivik K, Sweetman A, Pacyna JM, Jones KC. Towards a global historical emission inventory for selected PCB congeners-a mass balance approach. 1. Global production and consumption. Sci Total Environ. 2002;290(1-3):181-98.

10. Lee HG, Yang JH. PCB126 induces apoptosis of chondrocytes via ROSdependent pathways. Osteoarthritis Cartilage. 2012;20(10):1179-85. doi:10.1016/j.joca.2012.06.004.

11. Waye A, Trudeau VL. Neuroendocrine disruption: more than hormones are upset. J Toxicol Environ Health B Crit Rev. 2011;14(5-7):270-91. doi:10.1080/10937404.2011.578273.

12. Gibbons GF, Wiggins D, Brown AM, Hebbachi AM. Synthesis and function of hepatic very-low-density lipoprotein. Biochem Soc Trans. 2004;32(Pt 1):59-64.

13. Gordon DA, Jamil H, Gregg RE, Olofsson SO, Boren J. Inhibition of the microsomal triglyceride transfer protein blocks the first step of apolipoprotein B lipoprotein assembly but not the addition of bulk core lipids in the second step. J Biol Chem. 1996;271(51):33047-53.

14. Wetterau JR, Lin MCM, Jamil H. Microsomal triglyceride transfer protein. Biochimica et Biophysica Acta (BBA) Lipids and Lipid Metabolism. 1997;1345(2):136-50

15. Liang J, Oelkers P, Guo C, Chu PC, Dixon JL, Ginsberg HN, et al. Overexpression of human diacylglycerol acyltransferase 1, acyl-coa:cholesterol acyltransferase 1, or acyl-CoA:cholesterol acyltransferase 2 stimulates secretion of apolipoprotein B-containing lipoproteins in McA-RH7777 cells. J Biol Chem. 2004;279(43): 44938-44. doi:10.1074/jbc.M408507200.

16. Stone SJ, Myers HM, Watkins SM, Brown BE, Feingold KR, Elias PM, et al. Lipopenia and skin barrier abnormalities in DGAT2-deficient mice. J Biol Chem. 2004;279(12):11767-76. doi:10.1074/jbc.M311000200.

17. Hua X, Wu J, Goldstein JL, Brown MS, Hobbs HH. Structure of the human gene encoding sterol regulatory element binding protein-1 (SREBF1) and localization of SREBF1 and SREBF2 to chromosomes 17p11.2 and 22q13. Genomics. 1995;25(3):667-73.

18. Shimomura I, Shimano H, Horton JD, Goldstein JL, Brown MS. Differential expression of exons $1 \mathrm{a}$ and $1 \mathrm{c}$ in mRNAs for sterol regulatory element binding protein-1 in human and mouse organs and cultured cells. J Clin Invest. 1997;99(5):838-45. doi:10.1172/JCl119247.

19. Shimano H, Yahagi N, Amemiya-Kudo M, Hasty AH, Osuga J, Tamura Y, et al. Sterol regulatory element-binding protein-1 as a key transcription factor for nutritional induction of lipogenic enzyme genes. J Biol Chem. 1999; 274(50):35832-9.

20. Cauli O, Piedrafita B, Llansola M, Felipo V. Gender differential effects of developmental exposure to methyl-mercury, polychlorinated biphenyls 126 or 153 , or its combinations on motor activity and coordination. Toxicol. 2013;311(1-2):61-8. doi:10.1016/j.tox.2012.11.016.

21. Carpenter DO. Polychlorinated biphenyls (PCBs): routes of exposure and effects on human health. Rev Environ Health. 2006;21(1):1-23.

22. Vorrink SU, Severson PL, Kulak MV, Futscher BW, Domann FE. Hypoxia perturbs aryl hydrocarbon receptor signaling and CYP1A1 expression induced by PCB 126 in human skin and liver-derived cell lines. Toxicol Appl Pharmacol. 2014;274(3):408-16. doi:10.1016/j.taap.2013.12.002.

23. Lai I, Chai Y, Simmons D, Luthe G, Coleman MC, Spitz D, et al. Acute toxicity of 3,3',4,4',5-pentachlorobiphenyl (PCB 126) in male Sprague-Dawley rats: effects on hepatic oxidative stress, glutathione and metals status. Environ Int. 2010;36(8):918-23. doi:10.1016/j.envint.2009.11.002.

24. Wahlang B, Falkner KC, Gregory B, Ansert D, Young D, Conklin DJ, et al. Polychlorinated biphenyl 153 is a diet-dependent obesogen that worsens nonalcoholic fatty liver disease in male C57BL6/J mice. J Nutr Biochem. 2013;24(9):1587-95. doi:10.1016/j.jnutbio.2013.01.009.

25. Arsenescu V, Arsenescu RI, King V, Swanson H, Cassis LA. Polychlorinated biphenyl-77 induces adipocyte differentiation and proinflammatory adipokines and promotes obesity and atherosclerosis. Environ Health Perspect. 2008;116(6):761-8. doi:10.1289/ehp.10554.

26. Raabe M, Flynn LM, Zlot CH, Wong JS, Veniant MM, Hamilton RL, et al. Knockout of the abetalipoproteinemia gene in mice: Reduced lipoprotein secretion in heterozygotes and embryonic lethality in homozygotes. PNAS. 1998;95(15):8686-91. doi:10.1073/pnas.95.15.8686.

27. Raabe M, Veniant MM, Sullivan MA, Zlot CH, Bjorkegren J, Nielsen LB, et al. Analysis of the role of microsomal triglyceride transfer protein in the liver of tissue-specific knockout mice. J Clin Invest. 1999;103(9):1287-98. 
28. Gambino R, Cassader M, Pagano G, Durazzo M, Musso G. Polymorphism in microsomal triglyceride transfer protein: a link between liver disease and atherogenic postprandial lipid profile in NASH? Hepatol. 2007;45(5):1097-107. doi:10.1002/hep.21631.

29. Chapados NA, Lavoie JM. Exercise training increases hepatic endoplasmic reticulum (er) stress protein expression in MTP-inhibited high-fat fed rats. Cell Biochem Funct. 2010;28(3):202-10. doi:10.1002/cbf.1643.

30. Cuchel M, Bloedon LT, Szapary PO, Kolansky DM, Wolfe ML, Sarkis A, et al. Inhibition of Microsomal Triglyceride Transfer Protein in Familial Hypercholesterolemia. N Engl J Med. 2007;356(2):148-56. doi:10.1056/ NEJMoa061189.

31. Miyazaki MS, Kodama H, Yamada H, Nagata K, Toriumi W, Kitamura K, et al. Hepatic and intestinal changes in rats treated with T-0126, a microsomal triglyceride transfer protein (mtp) inhibitor. J Toxicol Sci. 2007;32(2):161-77

32. Dikkers A, Annema W, de Boer JF, lqbal J, Hussain MM, Tietge UJ. Differential impact of hepatic deficiency and total body inhibition of MTP on cholesterol metabolism and RCT in mice. J Lipid Res. 2014;55(5):816-25. doi:10.1194/jlr.M042986.

33. Taghibiglou C, Carpentier A, Van Iderstine SC, Chen B, Rudy D, Aiton A, et al. Mechanisms of hepatic very low density lipoprotein overproduction in insulin resistance. Evidence for enhanced lipoprotein assembly, reduced intracellular apob degradation, and increased microsomal triglyceride transfer protein in a fructose-fed hamster model. J Biol Chem. 2000;275(12):8416-25. doi:10.1074/jbc.275.12.8416.

34. Tietge UJ, Bakillah A, Maugeais C, Tsukamoto K, Hussain M, Rader DJ. Hepatic overexpression of microsomal triglyceride transfer protein (MTP) results in increased in vivo secretion of VLDL triglycerides and apolipoprotein B. J Lipid Res. 1999;40(11):2134-9.

35. Qiu W, Taghibiglou C, Avramoglu RK, Van Iderstine SC, Naples M, Ashrafpour $\mathrm{H}$, et al. Oleate-mediated stimulation of microsomal triglyceride transfer protein (MTP) gene promoter: implications for hepatic MTP overexpression in insulin resistance. Biochemistry. 2005:44(8):3041-9. doi:10.1021/bi047803+.

36. Arrebola JP, Ocana-Riola R, Arrebola-Moreno AL, Fernandez-Rodriguez M, Martin-Olmedo P, Fernandez MF, et al. Associations of accumulated exposure to persistent organic pollutants with serum lipids and obesity in an adult cohort from Southern Spain. Environ Pollut. 2014;195C:9-15. doi:10.1016/j.envpol.2014.08.003.

37. Bell FP, Iverson F, Arnold D, Vidmar TJ. Long-term effects of Aroclor 1254 (PCBs) on plasma lipid and carnitine concentrations in rhesus monkey. Toxicol. 1994;89(2):139-53.

38. Oda H, Fukui H, Hitomi $Y$, Yoshida A. Alteration of serum lipoprotein metabolism by polychlorinated biphenyls and methionine in rats fed a soybean protein diet. J Nutr. 1991;121(7):925-33.

39. Singh HJ, Syeda TU, Kakalij RM, Prasad W, Diwan PV. Erythropoietin protects polychlorinated biphenyl (Aroclor 1254) induced neurotoxicity in mice. Eur J Pharmacol. 2013;707(1-3):54-60. doi:10.1016/j.ejphar.2013.03.009.

40. Sandberg PO, Glaumann H. Studies on the cellular toxicity of polychlorinated biphenyls (PCBs) partial block and alteration of intracellular migration of lipoprotein particles in rat liver. Exp Mol Pathol. 1980;32(1):1-22.

41. Adiels M, Taskinen MR, Packard C, Caslake M, Soro-Paavonen A, Westerbacka J, et al. Overproduction of large VLDL particles is driven by increased liver fat content in man. Diabetologia. 2006:49(4):755-65.

42. Hiukka A, Fruchart-Najib J, Leinonen E, Hilden H, Fruchart JC, Taskinen MR. Alterations of lipids and apolipoprotein CIII in very low density lipoprotein subspecies in type 2 diabetes. Diabetologia. 2005;48(6):1207-15. doi:10.1007/s00125-005-1753-z.

43. Rowan-Carroll A, Halappanavar S, Williams A, Somers CM, Yauk CL. Mice exposed in situ to urban air pollution exhibit pulmonary alterations in gene expression in the lipid droplet synthesis pathways. Environ Mol Mutagen. 2013;54(4):240-9. doi:10.1002/em.21768.

44. Monetti M, Levin MC, Watt MJ, Sajan MP, Marmor S, Hubbard BK, et al. Dissociation of hepatic steatosis and insulin resistance in mice overexpressing DGAT in the liver. Cell Metab. 2007;6(1):69-78. doi:10.1016/j.cmet.2007.05.005.

45. Choi CS, Savage DB, Kulkarni A, Yu XX, Liu ZX, Morino K, et al. Suppression of diacylglycerol acyltransferase-2 (DGAT2), but not DGAT1, with antisense oligonucleotides reverses diet-induced hepatic steatosis and insulin resistance. J Biol Chem. 2007;282(31):22678-88. doi:10.1074/jbc.M704213200.

46. Liu Y, Millar JS, Cromley DA, Graham M, Crooke R, Billheimer JT, et al. Knockdown of acyl-CoA:diacylglycerol acyltransferase 2 with antisense oligonucleotide reduces VLDL TG and ApoB secretion in mice. Biochim Biophys Acta. 2008;1781(3):97-104. doi:10.1016/j.bbalip.2008.01.001.

47. Yu XX, Murray SF, Pandey SK, Booten SL, Bao D, Song XZ, et al. Antisense oligonucleotide reduction of DGAT2 expression improves hepatic steatosis and hyperlipidemia in obese mice. Hepatol. 2005;42(2):362-71. doi:10.1002/ hep.20783.

48. Zammit VA. Hepatic triacylglycerol synthesis and secretion: DGAT2 as the link between glycaemia and triglyceridaemia. Biochem J. 2013;451(1):1-12. doi:10.1042/BJ20121689.

49. Wurie HR, Buckett L, Zammit VA. Diacylglycerol acyltransferase 2 acts upstream of diacylglycerol acyltransferase 1 and utilizes nascent diglycerides and de novo synthesized fatty acids in HepG2 cells. FEBS J. 2012;279(17):3033-47. doi:10.1111/j.1742-4658.2012.08684.x.

50. Shimano H, Horton JD, Shimomura I, Hammer RE, Brown MS, Goldstein JL. Isoform 1c of sterol regulatory element binding protein is less active than isoform 1a in livers of transgenic mice and in cultured cells. J Clin Invest. 1997:99(5):846-54. doi:10.1172/JCl119248.

51. Shimomura I, Shimano H, Korn BS, Bashmakov Y, Horton JD. Nuclear sterol regulatory element-binding proteins activate genes responsible for the entire program of unsaturated fatty acid biosynthesis in transgenic mouse liver. J Biol Chem. 1998:273(52):35299-306.

52. Ruzzin J, Petersen R, Meugnier E, Madsen L, Lock EJ, Lillefosse $H$, et al, Persistent organic pollutant exposure leads to insulin resistance syndrome. Environ Health Perspect. 2010;118(4):465-71. doi:10.1289/ehp.0901321.

53. National Toxicology Program. Toxicology and carcinogenesis studies of a binary mixture of 3,3',4,4',5-pentachlorobiphenyl (PCB126) and 2,2',4,4',5,5'hexachlorobiphenyl (PCB153) in female Harlan Sprague-Dawley rats. 2006 Aug:(530):1-258.

54. Patti ME CS. The role of mitochondria in the pathogenesis of Type 2 Diabetes. Endocrine reviews. 2010;31(3):364-95. doi:10.1210/er.2009-0027.

55. Szendroedi J, Phielix E, Roden M. The role of mitochondria in insulin resistance and type 2 diabetes mellitus. Nat Rev Endocrinol. 2012;8(2):92-103. doi:10.1038/nrendo.2011.138.

\section{Submit your next manuscript to BioMed Central and we will help you at every step:}

- We accept pre-submission inquiries

- Our selector tool helps you to find the most relevant journal

- We provide round the clock customer support

- Convenient online submission

- Thorough peer review

- Inclusion in PubMed and all major indexing services

- Maximum visibility for your research

Submit your manuscript at www.biomedcentral.com/submit 